\title{
Research on Multi-point Practice of Doctors Under the Background of Graded Diagnosis and Treatment
}

\author{
Cuiyue Zhu ${ }^{1}$, Yongyan Wang ${ }^{1}$, Haitong $\mathrm{Zhu}^{2}$, Jian Zhang ${ }^{3}$, * \\ ${ }^{1}$ Graduate School of Tianjin University of Traditional Chinese Medicine, Tianjin, China \\ ${ }^{2}$ Guanyun County People's Hospital, Lianyungang City, Lianyungang, China \\ ${ }^{3}$ School of Management, Tianjin University of Traditional Chinese Medicine, Tianjin, China
}

Email address:

Zjian619@126.com (Jian Zhang)

${ }^{*}$ Corresponding author

\section{To cite this article:}

Cuiyue Zhu, Yongyan Wang, Haitong Zhu, Jian Zhang. Research on Multi-point Practice of Doctors Under the Background of Graded Diagnosis and Treatment. International Journal of Education, Culture and Society. Vol. 6, No. 3, 2021, pp. 79-84. doi: $10.11648 /$ j.ijecs.20210603.12

Received: February 10, 2021; Accepted: March 1, 2021; Published: May 20, 2021

\begin{abstract}
The multi-point practice of doctors promotes the rational flow of medical staff through the role of the market in the allocation of resources, thereby realizing the rational allocation of health human resources, promoting the diversification of medical services that reflect the labor value of medical staff, and playing an important role in accelerating the reform of public hospitals effect. This article first analyzes the doctor's multi-point practice system environment, the interests and behaviors of the main participants, and then sorts out the gradual reform of the doctor's multi-point practice policy and the policy constraints on the doctor's multi-point practice, combined with the multi-point practice of doctors in Jiangsu Province. The implementation status shares the implementation of the doctor's multi-point practice policy. The results show that the doctor's multi-point practice attitude, subjective norms, and perceptual control are high, but the behavior intention is difficult to translate into actual behavior. Finally, based on the analysis results, it is from the policy subject, the policy stakeholder, and the policy. The environment and other aspects put forward corresponding strategies to further promote scientific and reasonable medical models, improve the social value of medical staff, mobilize the enthusiasm of doctors, and improve the hierarchical diagnosis and treatment service system.
\end{abstract}

Keywords: Multiple-site Physician Practice, Hierarchical Diagnosis System, Countermeasures

\section{Introduction}

At present, the allocation of health resources in China is unequal, large-scale medical institutions and hospitals are excessively working, and some resources of primary medical institutions are idle. It can be seen that the contradiction between the people that growing medical and health resources needs and unbalanced medical resources restricts the improvement of medical standards level [1]. In order to relieve such contradictions, the state has successively released policies for multi-point practice, aiming to equally distribute medical and health human resources and solve the problem of "difficult and expensive medical treatment". Since the implementation of the hierarchical diagnosis and treatment system in 2015, the multi-point practice registration policy for physicians has been relatively loose. However, resistance has been encountered in the implementation process, various reasons have been analyzed, and corresponding counter measurements of human and promoting great health human resources. It is of great significance to balance the phenomenon, promote the fairness of medical and health services, and protect the health of the people [2].

\section{Explanation of Related Concepts}

\subsection{Concept Interpretation of Graded Diagnosis and Treatment}

Hierarchical diagnosis and treatment tr to maximize the efficiency of medical resource allocation and use on the basis of the gradual diagnosis and treatment process, and to perfect 
patient management services. As a core system to guarantee citizens' right to health, it includes the first diagnosis in the grassroots community, hierarchical treatment, and two-way referral. The institutional requirements of the medical treatment process are the normative requirements related to medical treatment order, medical treatment process, and medical treatment behavior.

The United Kingdom is a typical representative of the national welfare medical security system model. It is also the first country to practice a hierarchical diagnosis and treatment system. Its three-tiered medical service network has a clear division of work, which including primary services provided by general practitioners for mild cases, and hospitals for acute or severe cases [3]. Secondary services provided by specialists and the tertiary services provided by teaching hospitals for more specialized treatment and nursing for critically ill patients. And the standardized management system of general practitioners ensures the service ability of primary medical institutions for hierarchical diagnosis and treatment. The United States uses medical insurance as a lever to guide patients to the community for the first diagnosis. On the basis of absorbing foreign experience, various regions have introduced plans that are in line with local conditions to promote hierarchical diagnosis and treatment practices, such as the family doctor contract system in Shanghai, the establishment of medical consortium in Beijing, and the implementation of "chronic disease first, three divisions" in Xiamen [4].

\subsection{Physicians Practice More}

There is no specific concept of multi-point practice of doctors in the world, but a system of free practice generally exists. Based on the top-level design, European and American countries have formulated reasonable laws and regulations, implemented scientific, reasonable, and efficient physician evaluation and mobility mechanisms, and encouraged the free flow of doctors on the basis of ensuring that the country can give basic health services. The government strengthened supervision and ensured the safety of medical order. Reliable and orderly, to maximize the sharing of medical resources. Encouraging doctors to continuously strengthen their own abilities, improve service attitudes and quality, and create personal brand images [5].

In China, multi-point practice of physicians means that physicians are engaged in diagnosis and treatment activities in two or more medical institutions, excluding physicians' out-of-office consultations, and physicians' participation in charity or public welfare circulating medical services, free consultations, emergency or disaster relief work. Participating in the implementation of basic and major public health service projects does not belong to the multi-point practice of doctors. There are three types of multi-point practice for doctors. One is the government-directed type, which only needs to be approved by the medical institution where the doctor is located; the second is the medical cooperation type, which requires the doctor's hospital to register and file with the health administration department; the third is the active employment type, where the doctor two or more practice locations can be selected. [6] The physician himself is required to apply to the health administration department to increase the practice location, but no written application from the dean of the first practice site is required. The registration management filing system is implemented and higher labor remuneration is obtained.

\subsection{The Relationship Between the Hierarchical Diagnosis and Treatment System and the Multi-point Practice of Doctors}

Hierarchical diagnosis and treatment is a system for optimizing the allocation of medical and health resources. Physician multi-point practice is an important promoter of making full use of medical and health personnel resources. They reinforce promote and cooperate with each other. The existing multi-point practice system for physicians has doctor units in the implementation process. The constraints of the human system, the pursuit of maximization of the hospital's interest in the market, and the lack of supporting measures in the promotion of policies have reduced the enthusiasm of doctors to engage in multi-point practice, which is not conducive to the rational allocation and orderly flow of medical and health resources [7]. Further improve and perfect the doctor's multi-point practice system under the perspective of graded diagnosis and treatment, ensure that doctors realize the transformation from a unit person to a free person, and mobilize their enthusiasm for multi-point practice, so as to meet the actual needs of graded diagnosis and realize medical and health ssanitation care as well as efficient allocation of resources [8].

\section{The Current Situation of Physicians' Multi-Point Practice}

\subsection{Policy Review}

Table 1. Summary of my country's doctors' multi-point practice policy.

\begin{tabular}{lll}
\hline Date & Policy name & Main content \\
\hline 2005.04 .30 & $\begin{array}{l}\text { Interim Provisions on the Management of } \\
\text { Physicians' Outing Consultation } \\
\text { Opinions of the CPC Central Committee and the }\end{array}$ & $\begin{array}{l}\text { Physicians are not allowed to go out for consultation without the approval of their medical } \\
\text { institution }\end{array}$ \\
2009.03 .17 & $\begin{array}{l}\text { State Council on Deepening the Reform of the } \\
\text { Medical and Health System }\end{array}$ & $\begin{array}{l}\text { Point out to start preliminary research, exploration, and multi-point practice of registered } \\
\text { physicians }\end{array}$ \\
2009.09 .11 & $\begin{array}{l}\text { Notice of the Ministry of Health on the Issues } \\
\text { Concerning the Multi-point Practice of Physicians }\end{array}$ & $\begin{array}{l}\text { Relevant regulations shall be made in accordance with the requirements of "piloting first and } \\
\text { gradually rolling out" }\end{array}$ \\
\hline
\end{tabular}




\begin{tabular}{|c|c|c|}
\hline Date & Policy name & Main content \\
\hline 2011.02 .28 & $\begin{array}{l}\text { Work Arrangements for the Pilot Reform of Public } \\
\text { Hospitals in } 2011\end{array}$ & $\begin{array}{l}\text { It clearly proposed to, the scope of the pilot program to all public hospital reform pilot cities and } \\
\text { other regions with conditions, to loosen the applicable personnel requirements to attending } \\
\text { physicians, and to increase the number of locations for practice. Encouraging practicing } \\
\text { physicians in public hospitals to carry out practicing activities in primary medical and health } \\
\text { institutions }\end{array}$ \\
\hline 2011.07.12 & $\begin{array}{l}\text { The Notice of the General Office of the Ministry of } \\
\text { Health on Expanding the Pilot Scope of } \\
\text { Multi-point Practice for Physicians }\end{array}$ & $\begin{array}{l}\text { Decided to expand the pilot range of multi-point practice to the whole country. Eligible } \\
\text { physicians can apply for an additional } 2 \text { practice locations }\end{array}$ \\
\hline 2014.11 .05 & $\begin{array}{l}\text { The "Notice on Printing and Distributing Ruo } \\
\text { Thousand Opinions on Promoting and Regulating } \\
\text { Multi-point Practice of Physicians }\end{array}$ & $\begin{array}{l}\text { The regulations and conditions for doctors' multi-point practice have been refined and adjusted. } \\
\text { The doctor's application requirements have been revised to "have qualifications for intermediate } \\
\text { and above professional and technical positions, and have been engaged in the same professional } \\
\text { for more than } 5 \text { years", allowing clinical, dental and traditional Chinese medicine doctors to } \\
\text { practice at multiple points; simplify relevant registration procedures and explore the feasibility } \\
\text { of filing management. Regional registration can be implemented in places where conditions are } \\
\text { ripe, clearly specifying the personnel management system and medical responsibility } \\
\text { management; the restriction on practice locations has been revised to "multiple practice in two or } \\
\text { more medical institutions during the valid registration period" }\end{array}$ \\
\hline 2017.02 .28 & $\begin{array}{l}\text { Administrative Measures for Physician Practice } \\
\text { Registration }\end{array}$ & $\begin{array}{l}\text { It is stipulated that physicians who practice in multiple institutions at the same practice location } \\
\text { should determine one institution as their main practice institution and apply for registration with } \\
\text { the health and family planning administrative department that approves the institution's practice; } \\
\text { for other institutions that intend to practice, they should apply to the institution's health The } \\
\text { family planning administrative department shall apply for filing separately and indicate the name } \\
\text { of the practice institution where it is located. Realize "one time registration, valid area" }\end{array}$ \\
\hline
\end{tabular}

As can be seen from Table 1, the period from 2009 to 2011 is the pilot exploration stage, the period from 2011 to 2014 is the promotion stage, and the period after 2014 is the full implementation stage. After the introduction of the national-level policy, Jiangsu Province actively responded to the call of the country and proclaim corresponding policies to promote the development of doctors in multiple areas. In June 2015, the Provincial Department of Health issued the
"Administrative Measures for Multi-point Practice of Physicians in Jiangsu Province".

\subsection{Research Status}

Taking Jiangsu Province as an example, the registration status of physicians practicing in multiple locations in the 13 cities of Jiangsu Province is shown in Table 2.

Table 2. Status of multi-point practice registration.

\begin{tabular}{|c|c|c|c|c|c|c|c|c|c|}
\hline \multirow{2}{*}{ Area } & \multicolumn{3}{|c|}{ Number of physicians (person) } & \multicolumn{6}{|c|}{ Number of multi-point practicing physicians (person) } \\
\hline & Total & Male & Female & total & Clinical & Oral cavity & Chinese Medicine & Male & Female \\
\hline Nanjing & 25024 & 12641 & 12383 & 101 & 85 & 3 & 13 & 58 & 43 \\
\hline Wuxi & 16825 & 9329 & 7496 & 66 & 49 & 7 & 10 & 40 & 26 \\
\hline Xuzhou & 20918 & 11967 & 8951 & 137 & 112 & 12 & 13 & 91 & 46 \\
\hline Changzhou & 11431 & 6204 & 5227 & 66 & 51 & 3 & 12 & 48 & 18 \\
\hline SuZhou & 27172 & 14710 & 12462 & 212 & 167 & 9 & 36 & 144 & 68 \\
\hline Nantong & 17045 & 9691 & 7354 & 54 & 38 & 0 & 16 & 34 & 20 \\
\hline Lianyungang & 9534 & 5607 & 3927 & 30 & 26 & 1 & 3 & 16 & 14 \\
\hline Huaian & 10758 & 6767 & 3991 & 62 & 55 & 4 & 3 & 44 & 18 \\
\hline Yancheng & 16669 & 10046 & 6623 & 49 & 42 & 3 & 4 & 29 & 20 \\
\hline Yangzhou & 10452 & 6164 & 4288 & 35 & 28 & 1 & 6 & 19 & 16 \\
\hline Zhenjiang & 7445 & 4338 & 3107 & 56 & 47 & 1 & 8 & 38 & 18 \\
\hline Taizhou & 11168 & 6954 & 4214 & 37 & 30 & 3 & 4 & 22 & 15 \\
\hline Suqian & 9560 & 6126 & 3434 & 70 & 55 & 8 & 7 & 50 & 20 \\
\hline Total & 19401 & 110544 & 83457 & 975 & 785 & 55 & 135 & 633 & 342 \\
\hline
\end{tabular}

As shown in Table 2, the number of registered multi-site physicians in the province accounted for $0.5 \%$ (975/194 001) of the total number of physicians, of which Suzhou City registered multi-site physicians accounted for the largest number of registered multi-site physicians in the province, accounting for It is $21.7 \%(212 / 975)$. The least is Lianyungang City, which accounts for 3.0\% (30/975). In terms of gender, male physicians have more registered practitioners than women, accounting for $64.9 \%(633 / 975)$ In terms of practice types, the number of clinicians registered for multipoint practice is the largest, accounting for $80.5 \%$ (785/975), and the number of dentists registered for multipoint practice is the least, accounting for $5.6 \%$ (55/975). As shown in Table 2, Suzhou registered multi-site practicing physicians accounted for the largest percentage of the number of physicians in the city, accounting for $0.78 \%(212 / 27172)$.

The multi-point practice policy for physicians can enable the reasonable distribution of medical resources among medical institutions at all levels, reduce the phenomenon of unfairness, and at the same time facilitate the flow of talents among medical institutions in the context of hierarchical diagnosis and treatment. The multi-point practice of physicians has been 
affirmed by the policy, and the registration conditions are relatively loose, but the implementation and implementation of this policy has not been effective. [9] The main manifestation is the small number of registrations, the unbalanced distribution of practice types of multi-point practicing physicians, and large regional differences. Mainly distributed in economically developed areas.

\section{Analysis of Existing Problems}

The promotion of doctors' multi-point practice is inevitably to increasing the income of doctors, integrating health human resources, reducing the cost of medical services, and improving the quality of medical services. It is the trend of medical reform and development, which is conducive to the development and progress of my country's medical industry [10]. However, the result in implementation process does not very successfully. Through the analysis of the existing problems, the corresponding countermeasures and suggestions are put forward to provide a certain reference basis for further in-depth doctors' multi-point practice problems.

\subsection{The Quality of Medical Services Is Difficult to Guarantee}

At present, there are many medical accidents caused by doctors' multi-site practice. The main reason is that township hospitals and community medical and health service institutions are often so small in scale that there are a lot of relatively incomplete rules and regulations. These towns lack of advanced medical equipment and large-scale general hospitals. There is a certain gap, which makes it impossible for doctors to provide patients with more accurate diagnosis and treatment results even with higher levels of diagnosis and treatment, thereby increasing the probability of medical accidents. In addition, medical and health services need to be professional and continuous. Patient consultation requires follow-up work. Most multi-point practitioners lack the continuity of patient consultation, and the patient's later treatment lacks certain guarantees. Physicians in primary medical institutions The inability to deal with the emergencies of patients in the later period will make it difficult to guarantee the expected diagnosis and treatment results. And there even will are medical accidents, which has caused a great obstacle to the practice of multi-point practice of doctors [11].

\subsection{Medical Damage or Disputes are Difficult to Deal With}

In November 2014, the "Several Opinions on Promoting and Regulating the Multi-point Practice of Physicians" was formulated, which stipulates that if a physician experiences medical damage or medical disputes in the process of multi-point practice, the medical institution that caused the medical damage or medical dispute should be handled by the medical institution concerned. And the doctors deal with it in accordance with relevant laws and regulations, and other non-participant medical institutions do not need to bear the related responsibilities for medical damage or medical disputes [12]. This does not solve the problem of whether the practitioner needs to directly face the patient and assume responsibility. Therefore, when a doctor has a medical malpractice or a medical dispute in the course of practicing, it is difficult to deal with the problem of responsibility definition. In many cases, the practicing doctor may be directly liable for tort liability.

\subsection{Doctors' Profit-Seeking Behavior Is Difficult to Control}

After the implementation of the practice of doctors in multiple locations, we can see doctors in multiple places at the same time, which will inevitably increase the income of doctors. Some doctors are driven by benefits and generate profit-driven behaviors, lacking corresponding specific regulations and system constraints. On the one hand, due to the pursuit of money, doctors may resell patients or transfer patients indiscriminately. On the other hand, doctors consider the maximization of economic benefits when treating patients, which will violate the professional ethics of saving the dead and helping the wounded. Medical ethics and other behaviors, multi-point practice may become a way for doctors to seek personal gain [13]. If the practice of practicing doctors does not have a clear supervision body and system for their profit-seeking behaviors, those with multiple points of practice will have excessive medical behaviors in primary medical institutions. Exacerbateing the problem of "expensive medical care" for the people.

\subsection{The First Practice Institution Is Difficult to Support}

After doctors carry out multi-point practice diagnosis and treatment activities, the continuity and uniformity of the management of doctors by the first practice institution will be impacted and challenged. Doctors participating in multi-site practice are usually well-known experts. If they are often busy going out to see a doctor, they will leave their jobs at will and affect the daily work order of the hospital, which will lead to the weakening or even emptiness of the command of the hospital management. In addition, doctors in large general hospitals are responsible for heavy medical, teaching, and research tasks. The implementation of multiple practices will inevitably make it difficult for doctors to have enough time to study medical topics and guide young doctors. New technology in the first practice institution, The development of new projects and personnel training will also be greatly affected. Before applying for multi-point practice, doctors need to obtain the consent of the first practice institution in advance, so as to ensure the medical effect of the doctor in the first practice institution. However, most public hospitals with strong comprehensive strength currently do not support doctors' multi-point practice behavior. Under the current system, the growth of doctors is inseparable from the platform of hospitals. When training doctors, medical and health institutions need to spend a lot of manpower and financial resources. Implementing more doctors' practice will break the talent monopoly of large hospitals. High-quality medical and health resources will flow outwards. 


\section{Countermeasure}

\subsection{Establish an Access and Supervision Mechanism for Multi-point Practice to Ensure the Quality of Medical Services}

First of all, we must strictly control the entry threshold and conduct a qualification review for multi-point practice of physicians. After the qualification review is passed, a multi-point practice license can be issued, and a validity period must be established for it. After the expiration, kit is necessary to reapply and register at the designated place. Secondly, it is necessary to conduct qualification review of medical institutions applying for multi-point practice, and there shall be no circumstances such as over-limit practice. In terms of supervision, the local medical association can supervise and evaluate the practice of multi-point practicing doctors. The medical association needs to report the results of the supervision and evaluation to the local administrative department [14]. Using this as the doctor's Enough to continue to apply for the qualification as a multipoint practicing physician.

\subsection{Clarify the Medical Responsibilities of Multiple Practitioners and Explore Ways to Share Responsibility and Risk}

Multi-point practicing physicians should sign a contract with the employed medical service organization and list the rights and obligations of both employers, such as the working hours and locations of multi-point practicing physicians, the content of medical services, salary remuneration, sharing of tort liability, etc. In the case of medical damage or disputes, the employed medical service organization should be the main body of responsibility, and evaluate the size of the liability according to the signed contract and convert it into a certain compensation ratio. In addition, a judicial appraisal agency for medical damages or disputes can be established to appraise the division of responsibilities for medical malpractices, and professional insurance companies can assume the obligation of compensation. This can prevent medical institutions from spending too much energy and paying high compensation due to medical accidents, and it can also enable patients to be resolved in time when they encounter medical damage.

\subsection{Coordinate the Allocation of Time for Practicing Physicians, Establish and Improve the Coordination Mechanism Among Practicing Institutions}

The "4+1" model in Japan and the United Kingdom stipulates that medical practitioners should work in the first practice institution at least 4 days a week and visit other medical service institutions for the remaining 1 day. Practicing doctors in the United States are divided by regional registration. Practicing doctors can serve different medical service institutions in the state where they are registered, but they need to visit a community hospital once a week. We can learn from the measures of Japan, the United Kingdom, the United States and other countries to coordinate the management of the practice time of multiple practitioners to prevent practitioners from affecting their health and the quality of medical services due to excessive working hours [15]. In addition, under the current medical and health service system, the status of practicing doctors has not been converted from a "unit person" to a "social person" status, which also involves doctors' social security and other issues. It is necessary to further explore and establish a sound coordination mechanism between different medical service institutions.

\subsection{Strengthen the Internal Management of the First Practice Institution, and Promulgate Supporting Regulations for Multiple Practice as Soon as Possible}

The first practice institution should strengthen the management of multi-site practicing doctors. The human resources department must develop a systematic and complete management system, including a performance appraisal system and a personnel salary system. Quantitative evaluation of doctors practicing at multiple points can not only standardize the workload of practicing doctors, but also ensure the work efficiency and medical quality of the first practice institution. In addition, the current series of documents on multi-point practice promulgated by the Ministry of Health are administrative rules and regulations in terms of legal effect, and they need to be raised to the legislative level to ensure the legal status of doctors in multi-point practice. At the same time, it is necessary to clarify that doctors practice in multiple points. The assessment methods and the legal relationship and responsibilities between the first, second and third practice institutions will further regulate the practice of doctors in multiple points.

\section{Conclusion}

Multi-point practice of doctors is an important part of the new medical reform, and its smooth implementation can promote the realization of graded diagnosis and treatment, two-way referral, and alleviate the problems of "difficult and expensive medical treatment". Although there are certain difficulties in the implementation of multi-point practice for physicians, the health administrative agency has improved its top-level design, and has done a good job of system and legal protection. Medical and health institutions at all levels actively responded and participated actively. The advancement will eventually achieve a good situation.

\section{References}

[1] Kasha B, Tan D. Physician group practice trends: a comprehensive review $[\mathrm{J}]$. Social Science Electronic Publishing, 2016, 2 (3): 1-8.

[2] Burns LR, Goldsmith JC, Sen A. Horizontal and vertical integration of physicians: a tale of two tails [J]. Advances in Health Care Management, 2016 (15): 39.

[3] OECD. Health care resources: physicians [EB/OL]. (2019-07-02) [2019-08-10].

[4] AMA. Physician practice benchmark survey [EB/OL]. (2019-06-01) [2019-09-10]. 
[5] Igel M, Stringer T. Stark Law Impact on Medical Practice [M]. New York: Springer International Publishing, 2015.

[6] Duston PS. Analyzing form, function and financing of the U.S. health care system [EB/OL]. (2015-12-01) [2019-08-25].

[7] A multi-agent system based on reactive decision rules for solving the caregiver routing problem in home health care $[\mathrm{J}]$. Eric Marcon, Sondes Chaabane, Yves Sallez, Thérèse Bonte, Damien Trentesaux. Simulation Modelling Practice and Theory, 2017.

[8] The Guy's and St Thomas's NHS Foundation Trust @ home service: an overview of a new service [J]. Geraldine A. Lee, Karen Titchener. London Journal of Primary Care, 2017.

[9] Ji Baoyi, Jiang Tao, Wu Yingxiong. Law comparison of physicians' multi-point practice and similar situations [J]. Jiangsu Health Service Management. 2018 (07).

[10] The progress, problems and countermeasures of the pilot multi-point practice of physicians in my country [J]. Li Yan, Wang Manwei, Li Li, Yao Hongyan, Xu Li, Liu Xiuru. Soft Science of Health. 2019 (12).
[11] HicksCourant Katherine, Kanter Genevieve P, Giuntoli Robert $\mathrm{L}$ et al. An increase in multi-site practices: The shifting paradigm for gynecologic cancer care delivery. [J] Gynecologic oncology, 2020.

[12] Zhu Chang'e, Sheng Mengfei, Song Baoxiang. Research on the reasons and countermeasures of the doctor's multi-point practice policy "applauded but not popular" [J]. Chinese General Practice. 2019 (01).

[13] Investigation on the multi-site practice status of physicians in the top three hospitals in Hangzhou [J]. Zhu Liyan, Feng Yingchao, Zhu Yanqin, Chen Shixue, Pu Tianlong. Modern hospital management. 2019 (05).

[14] Xu Xueran, Sun Qiang. Chongqing Medicine. Study on the status quo of the implementation of graded diagnosis and treatment in China [J]. 2019 (11).

[15] Li Yan, Wang Manwei, Li Li, Yao Hongyan, Xu Li, Liu Xiuru. The progress, problems and countermeasures of the pilot multi-point practice of physicians in my country [J]. Soft Science of Health. 2019 (12). 